\title{
BMJ Open Factors influencing rapid progress in child health in post-conflict Liberia: a mixed methods country case study on progress in child survival, 2000-2013
}

\author{
Marie A Brault, ${ }^{1}$ Stephen B Kennedy, ${ }^{2}$ Connie A Haley, ${ }^{3,4}$ Adolphus T Clarke, ${ }^{5}$ \\ Musu C Duworko, ${ }^{6}$ Phanuel Habimana, ${ }^{7}$ Sten H Vermund, ${ }^{3,8}$ Aaron M Kipp, ${ }^{3,4}$ \\ Kasonde Mwinga ${ }^{7}$
}

To cite: Brault MA, Kennedy SB, Haley CA, et al. Factors influencing rapid progress in child health in post-conflict Liberia: a mixed methods country case study on progress in child survival, 2000-2013. BMJ Open 2018;8:e021879. doi:10.1136/ bmjopen-2018-021879

- Prepublication history and additional material for this paper are available online. To view these files, please visit the journal online (http://dx.doi. org/10.1136/bmjopen-2018021879).

Received 22 January 2018 Revised 11 April 2018 Accepted 11 May 2018

Check for updates

(C) Author(s) (or their employer(s)) 2018. Re-use permitted under CC BY-NC. No commercial re-use. See rights and permissions. Published by BMJ.

For numbered affiliations see end of article.

Correspondence to

Dr Aaron M Kipp;

aaron.kipp@Vanderbilt.Edu

\section{ABSTRACT}

Objectives Only 12 countries in the WHO's African region met Millennium Development Goal 4 (MDG 4) to reduce under-five mortality by two-thirds by 2015 . Given the variability across the African region, a four-country mixed methods study was undertaken to examine barriers and facilitators of child survival prior to 2015. Liberia was selected for an in-depth case study due to its success in reducing under-five mortality by $73 \%$ and thus successfully meeting MDG 4. Liberia's success was particularly notable given the civil war that ended in 2003. We examined some factors contributing to their reductions in under-five mortality.

Design A case study mixed methods approach drawing on data from quantitative indicators, national documents and qualitative interviews was used to describe factors that enabled Liberia to rebuild their maternal, neonatal and child health (MNCH) programmes and reduce under-five mortality following the country's civil war.

Setting The interviews were conducted in Monrovia (Montserrado County) and the areas in and around Gbarnga, Liberia (Bong County, North Central region). Participants Key informant interviews were conducted with Ministry of Health officials, donor organisations, communitybased organisations involved in MNCH and healthcare workers. Focus group discussions were conducted with women who have experience accessing MNCH services. Results Three prominent factors contributed to the reduction in under-five mortality: national prioritisation of MNCH after the civil war; implementation of integrated packages of services that expanded access to key interventions and promoted intersectoral collaborations; and use of outreach campaigns, community health workers and trained traditional midwives to expand access to care and improve referrals.

Conclusions Although Liberia experiences continued challenges related to limited resources, Liberia's effective strategies and rapid progress may provide insights for reducing under-five mortality in other post-conflict settings.

\section{INTRODUCTION}

Under-five mortality has declined in sub-Saharan Africa from an estimated 180 deaths per 1000 live births in 1990 to 83 deaths per
Strengths and limitations of this study

- Presents qualitative and quantitative data on implementation of maternal, neonatal and child health (MNCH) interventions in Liberia, which has been understudied in Liberia.

- Most studies exploring progress in child survival only present qualitative data from key informants working within the healthcare system, but this paper also provides data from women attempting to access services for themselves and their children in both urban and rural contexts.

- For the review of national MNCH documents, policies and strategies were not issued until after 2007 due to the civil war. While these documents contained retrospective assessments of the preceding period, assessments of the impact of more recent policies or strategies were not available.

- The qualitative data were limited to a non-random sample of participants and conducted in two counties (one urban, one rural). It is possible that the changes in under-five mortality in these areas do not reflect changes at the national level and that the views and experiences of some participants do not reflect those from other areas of Liberia.

1000 in $2015,{ }^{1}$ yet this was not sufficient for this region to meet Millennium Development Goal (MDG) 4 of reducing under-five mortality by two-thirds between 1990 and 2015. ${ }^{2}$ Nevertheless, as of 2015, 12 African countries had met their MDG 4 goal. ${ }^{1}$ There is thus much interest in understanding why some countries met MDG 4 while others did not. Liberia witnessed a dramatic reduction in under-five mortality from 255 to 70 deaths per 1000 live births between 1990 and 2015 (figure 1). ${ }^{1}$ This $73 \%$ reduction in mortality rates means that Liberia effectively met MDG 4 ahead of schedule. Infant mortality saw a similar $69 \%$ reduction over the period, while neonatal mortality declined less rapidly. 

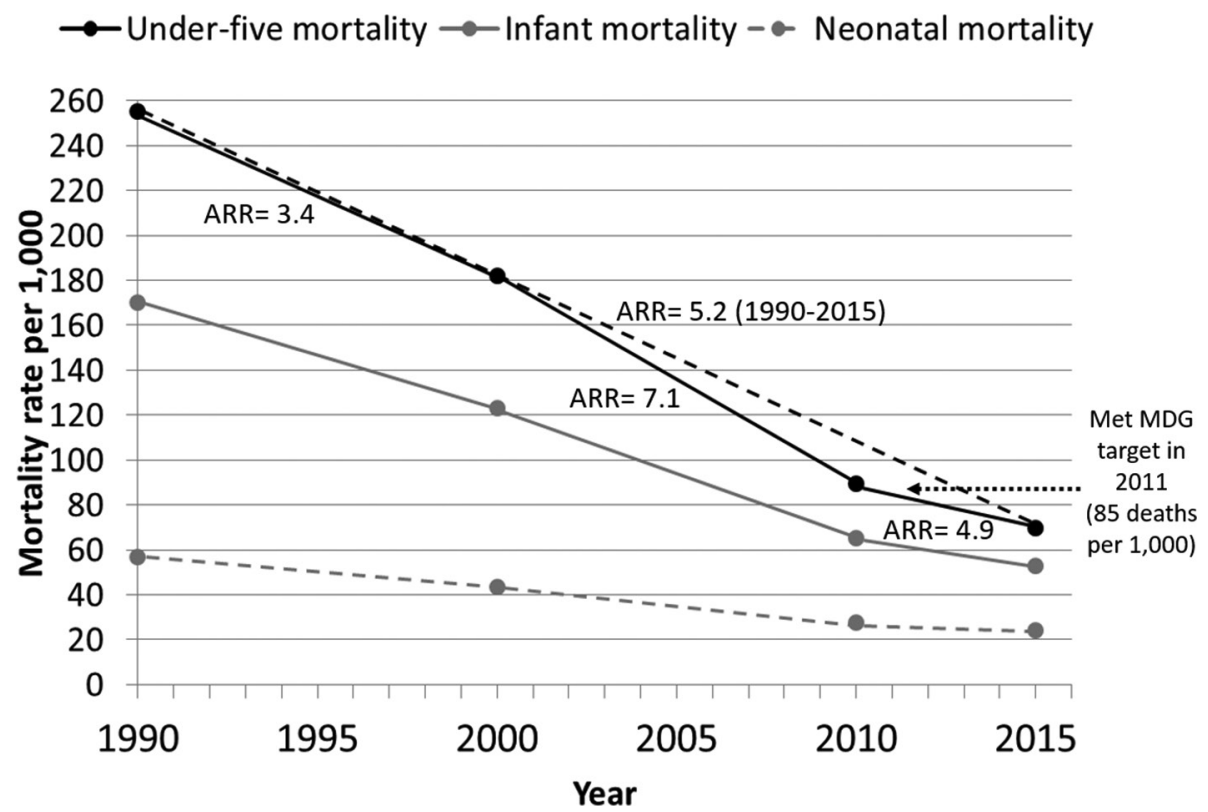

Figure 1 Under-five, infant and neonatal mortality rates for Liberia in 1990, 2000, 2010 and 2015 (solid circles) with annual rates of reduction (ARR) for each period (solid and dashed lines). Source: Levels and Trends in Child Mortality: Report 2015Estimates Developed by the United Nations Inter-agency Group for Child Mortality Estimation 1. Report and data accessed July 2015 from www.childmortality.org. MDG, Millennium Development Goal.

Liberia's accomplishments are especially notable given the 14years of civil war, ending in 2003, that destroyed most of the national infrastructure, eroded the country's social fabric and cost at least 200000 lives. Many health facilities were destroyed, skilled personnel were lost and essential medicines and supplies were scarce. ${ }^{3}$ Liberia emerged from this crisis with extremely limited health infrastructure and poor maternal, neonatal and child health $(\mathrm{MNCH})$ services. As a result of strong commitment and collaboration among the government and organisations from across civil society, the private sector and the general public, Liberia made notable gains towards re-establishing peace and security, revitalising the economy, strengthening governance and rebuilding health infrastructure, including MNCH services. ${ }^{3}$ Bornemisza $e t a t^{t}$ describe how the post-conflict period provides a unique opportunity for countries to address problems with their healthcare systems, as it is easier to create widespread change during a rebuilding period. Thus, identifying the specific factors that enabled Liberia to rapidly improve MNCH services after the civil crisis can inform other countries coming out of conflict or looking to make largescale changes. In addition, Liberia could use information from its post-conflict successes to inform and contribute to its own rebuilding efforts after the 2014-2015 Ebola virus epidemic.

A growing body of literature on $\mathrm{MNCH}$ in Liberia explores the country's efforts to implement $\mathrm{MNCH}$ interventions and expand access to care. Little research was published during the civil crisis and $\mathrm{MNCH}$ studies since have been primarily localised or quantitative,${ }^{5-15}$ focusing on access and utilisation of specific MNCH interventions. Much of the qualitative or mixed-methods literature from
Liberia to date has focused on maternal and reproductive health. ${ }^{16-19}$ Only one of the mixed-methods studies from Liberia evaluated integration and delivery of $\mathrm{MNCH}$ services. ${ }^{20} \mathrm{~A}$ few studies have reported on positive outcomes of specific interventions related to mobile data collection and monitoring, ${ }^{21} 22$ and training of community health workers ${ }^{23}$ and midwives to deliver $\mathrm{MNCH}$ interventions at the community level. ${ }^{24}{ }^{25}$ There have also been recent studies examining service usage, links between aspects of the healthcare system and the West African Ebola outbreak. ${ }^{26-29}$ There thus remains much to be understood about implementation of MNCH interventions and services and progress in reducing under-five mortality. While case studies from other countries making significant gains in child survival such as Niger, Uganda, Malawi, Ethiopia, Rwanda and Tanzania ${ }^{30-34}$ have evaluated system-level factors contributing to their success, only Tanzania included qualitative information from individuals attempting to access services for themselves or their children.

To contribute to the growing literature on how progress in reducing under-five mortality can be achieved in resource-limited countries, we conducted an in-depth case study from Liberia as part of a larger study seeking to understand the factors influencing progress in child survival in the Africa region among countries that were on-track (Liberia and Zambia) and not on-track (Kenya and Zimbabwe) to meet MDG $4 .{ }^{35-38}$ The period of interest was from the beginning of the MDG movement in 2000 through 2013 when the study was initiated. Our primary objective in the Liberia case study was to examine in-depth the specific factors influencing child survival and attainment of MDG 4 in a post-conflict setting in 
sub-Saharan Africa. By evaluating national policies and strategies, qualitative data and quantitative indicator data, we identified several overarching factors consistently reported to have improved access and utilisation of care for children under-five and reduced under-five mortality in Liberia.

\section{METHODS}

Our case study used country-level indicator data for the years closest to 2000, 2005 and 2013, a review of national policies and strategies issued between 2007 and 2013, following the civil conflict, and key informant interviews and focus groups with community women conducted in 2013.

\section{MNCH indicator data}

Prior to 2000, country-level data for core $\mathrm{MNCH}$ indicators monitored by Countdown to 2015 were not reliably available from many African countries, including Liberia. Most of Liberia's indicator data reported here were obtained from the World Bank Data Catalog, ${ }^{39}$ a repository of national, regional and global indicator data compiled from officially-recognised sources, including national Demographic and Health Surveys (DHS) and other national surveys. Data for indicators not readily available from the World Bank Data Catalog were obtained from the 2007 and 2013 Liberian DHS. ${ }^{401}$

We included indicator data most closely corresponding to the beginning and end of the study period to enable description of trends during the period. No DHS was conducted in Liberia between 1986 and 2007 due to the civil war, resulting in substantial missing data for the time period around 2000. We therefore also included 2007 DHS data to better visualise changes over time. Estimates were not always available for exact years 2000, 2007 and 2013, but we used data that were available within a 1 to 2 year window (see figure 2 ).

\section{Review of MNCH policies and strategies}

An information abstraction guide based on relevant global strategies related to child survival ${ }^{42-47}$ was developed to guide the document procurement and review process according to the following eight content areas: (1) healthcare system (including leadership, structure, human resources for health, access and utilisation, monitoring and evaluation and accountability), (2) national health strategies and policies (and regulations and laws, when applicable), (3) MNCH interventions, (4) clinical standards and guidelines, (5) commodities and essential medicines, (6) financial flows and resources, (7) effective partnerships and (8) other contextual factors (eg, conflict, political environment, sanitation and hygiene, nutrition and food security, education and human rights). When reviewing documents for information pertaining to the eight content areas, answers to the four overarching questions presented in table 1 were sought from each document.

Policies and strategies pertaining to overall national health, MNCH and those from other sectors related to $\mathrm{MNCH}$ (eg, education, water and sanitation, and

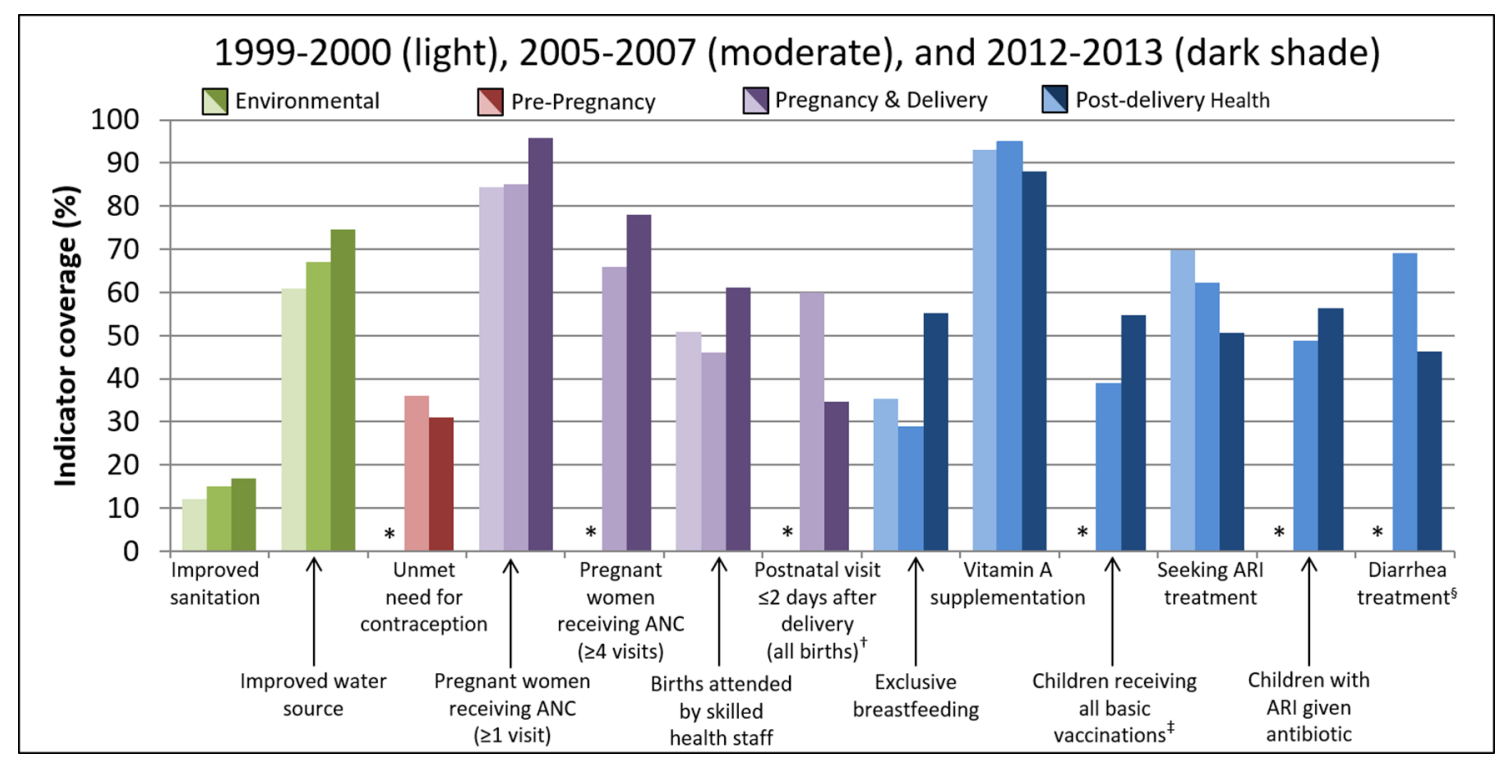

Figure 2 Changes in child survival indicator coverage in Liberia, 2000, 2007 and 2013*. *Estimates were not always available for years 2000, 2007 and 2013, in which case the nearest estimate between 1999 and 2000, 2005 and 2007 or 2012 and 2013 was used; data were not available for the six indicators showing an asterisk ( $\left(^{*}\right)$ during the 2000 time period. †Among all births, both inside and outside a health facility. ¥Children 12-23 months old who have received BCG, measles and three doses each of DPT and polio vaccine (excluding polio vaccine given at birth). §Children under-five receiving oral rehydration and continued feeding. Source: World Development Indicators Data Catalog from the World Bank (http://datacatalog.worldbank.org; accessed August 2015) and Liberia Demographic and Health Surveys. ANC, antenatal care; ARI, acute respiratory infection; DPT, diphtheria, pertussis and tetanus. 


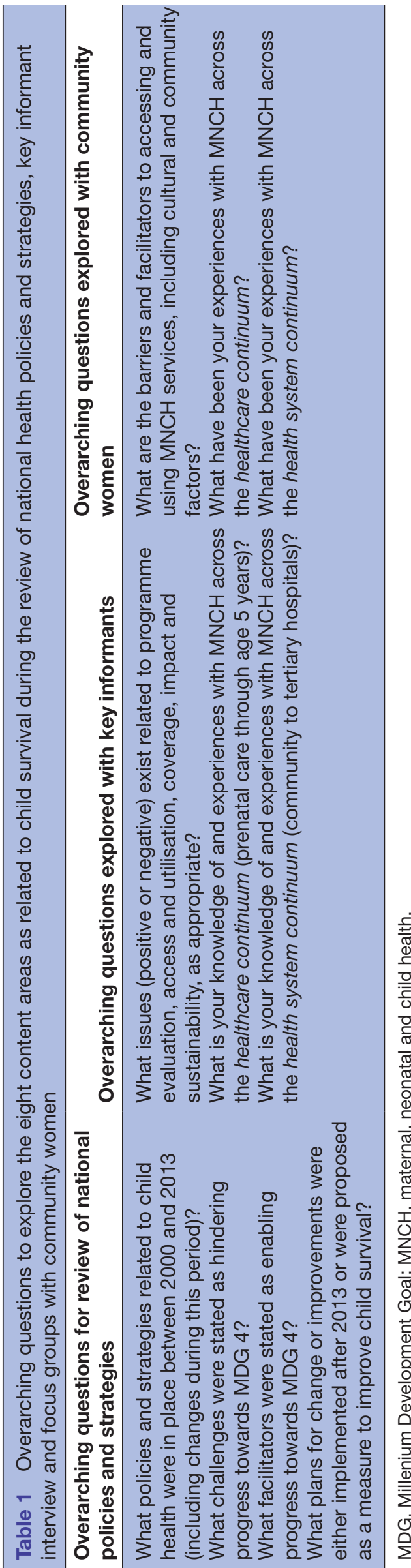

agriculture and nutrition) were obtained from the WHO African Region office, the WHO country focal points for Liberia and Liberia's Ministry of Health $(\mathrm{MOH}$; formerly Ministry of Health and Social Welfare). These documents were reviewed and any additional documents referenced and deemed important for the review (according to the abstraction guide) were obtained from $\mathrm{WHO}$ or $\mathrm{MOH}$. The final list of reviewed documents can be found in online supplementary table S1.

Each document was reviewed by two authors (MAB, $\mathrm{CAH}$ ), and information was recorded and summarised according to the abstraction guide. To avoid biased interpretation of the information documented, the abstracted information was reported as it was stated in the original source, and efforts were made not to overstate or minimise the original information or add commentary not contained in the source.

\section{Qualitative study procedures}

\section{Study location and participants}

Because major differences in MNCH often exist between urban and rural areas, participants for the qualitative study were included from both urban and rural areas. The design of the parent study (consisting of four country case studies) used country DHS to compare region-specific under-five mortality rates and declines in mortality over the study period. Urban and rural sites for the qualitative study were to be selected from the region or county whose annual rate of reduction in under-five mortality most closely matched that of the nation as a whole. In the case of Liberia, the 1986 DHS only reported mortality for three counties, while the 2007 DHS reported mortality rates for Monrovia and six regions comprised of three counties each. ${ }^{41}{ }^{48}$ As such, specific locations representative of Liberia's progress as a nation could not be conclusively identified. Following discussions with the in-country primary investigator (SBK), Monrovia (Montserrado County) was selected as the urban location with focus groups conducted in the Paynesville and New Kru Town areas, and the areas in and around Gbarnga (Bong County, North Central region) were chosen as the rural location with focus groups conducted in Gbarnga and Totota. While we cannot ensure these locations experienced declines in under-five mortality similar to Liberia as a whole, the other three country case studies were also largely conducted in the capital (urban site) and a nearby rural region. ${ }^{35} 3638$ Bong County was selected because it was reasonably accessible for conducting the study in a timely manner and was not markedly different from other areas of the country in terms of demographics and health infrastructure.

Data were obtained from semistructured, key informant interviews with $\mathrm{MOH}$ officials $(\mathrm{n}=11$ individuals interviewed), donor organisations $(n=8)$, community-based organisations (CBO) involved in $\mathrm{MNCH}$ $(\mathrm{n}=14)$ and healthcare workers (HCWs) $(\mathrm{n}=14)$. Data were also obtained from four focus group discussions, two in Monrovia ( $\mathrm{n}=16$ total participants) and two in 
Bong County $(n=21)$, with women who have experience accessing MNCH services. Interviews and focus groups were conducted between 30 October 2013 and 19 December 2013.

\section{Eligibility criteria and identification of study participants}

All participants, whether key informants or focus group women, were eligible for the study if they met the following criteria: (1) being 18 years of age or older, (2) having adequate knowledge or experiences related to childhood survival specified for each participant group below, (3) speaking English or Liberian English and (4) being able to provide written informed consent. Specific inclusion criteria for each key informant group included the following: national or provincial-level officials working in government-level healthcare system administration, policy-making, programme development, leadership or any aspect of MNCH (MOH officials); directors, managers or other leaders of entities providing financial or other aid for MNCH services, or international or national organisations focusing on $\mathrm{MNCH}$ or having $\mathrm{MNCH}$ as one component of their mission (Donor organisations); directors, leaders or managers working for a $\mathrm{CBO}$ involved in or providing referrals to $\mathrm{MNCH}$ services; and professionally trained physicians, nurses, clinical officers or other health-related staff working in a health facility providing $\mathrm{MNCH}$ care (healthcare professionals).

Similar numbers of participants from each key informant group were enrolled, and a range of ages, work experiences and positions/roles within each group was sought using department registers when available. Additionally, efforts were made to balance the number of urban and rural participants among the HCWs and $\mathrm{CBO}$ workers. Lists of potential key informants from each group were developed by the in-country research team with assistance, as needed, from the WHO National Professional Officer for Family Health and the MOH Deputy Programme Manager for the Expanded Programme on Immunisations. A letter signed by an official from the $\mathrm{MOH}$ was sent to each potential key informant participant informing them of the purpose of the study, risks and benefits of participation, and describing the interview process. These were followed up with a phone call or email to those interested. The final number of key informant interviews conducted was arrived at through a combination of approaches. Due to study logistics, we set a minimum number of 6 interviews to be conducted with both $\mathrm{MOH}$ and donor organisation representatives and a minimum of 12 interviews (half urban, half rural) to be conducted with both HCWs and CBO representatives. In an effort to achieve saturation, we prioritised diversity in the types of key informants we reached (online supplementary table S2). The in-country PI and research assistants monitored data collection and saturation.

Women were recruited to participate in focus groups using informational flyers or advertisements posted in different health centres and surrounding communities. As with the key informants, a balance was sought in the level of education and participants with live and deceased children, as well as a diversity of experiences and opinions regarding access and utilisation of $\mathrm{MNCH}$ services. The number of focus groups was determined at the outset of the study and constrained by study logistics. Written informed consent was obtained from all enrolled participants. Community women (online supplementary table S3) were provided a small monetary compensation for their participation.

\section{Interview and discussion guides}

Interview guides for key informants and discussion guides for focus groups with community women were developed, pilot tested through cognitive interviewing ${ }^{49}$ and revised as needed. The guides focused on experiences with MNCH services and barriers to and facilitators for improving child survival (table 1), pertaining to the eight content areas evaluated during the review of national health policies and strategies. Not all content areas were appropriate for each key informant group, but each topic was asked of at least two of the four groups. The content areas and overarching questions were developed to provide structure across the four country case studies of the parent study. However, they were intentionally broad to provide sufficient flexibility for participants within and across countries to discuss the issues most relevant to them. Focus group discussions with community women focused only on the healthcare system, MNCH interventions, medicines and contextual factors content areas. While participants could discuss the entire period from 2000 forward, most participants recalled more recent information and experiences.

\section{Data collection}

Prior to conducting interviews and focus group discussions, participants completed a brief survey to obtain basic demographic information, MNCH-related work experience (key informants only), socioeconomic information (focus group women only) and/or information on births and under-five deaths in the household (focus group women only).

Key informant interviews were conducted in English by one research assistant using the appropriate interview guide and were audio-recorded. Key informants were encouraged to provide their perspectives openly and discuss a range of barriers and facilitators to child survival. Interviews typically lasted $60-90 \mathrm{~min}$. The focus group discussions were conducted in Liberian English and were audio-recorded. Two Liberian research assistants (one male and one female) were present at each focus group to facilitate discussion and note-taking. Focus group participants were encouraged to provide their opinions openly, and research assistants were trained in techniques to promote open discussion. Focus groups typically lasted between $1 \frac{1 / 2}{2}$ and 2 hours.

The researchers on this study included individuals with knowledge and experience of $\mathrm{MNCH}$ at the national and international levels and who had prior experience with health research in Liberia. Key research team members 
had prior experience with qualitative and quantitative research methods and research ethics. An in-person methods training was held to ensure high-quality data across sites. Ongoing remote training and troubleshooting was provided to the research team during the piloting and data collection stages of the study. To promote reflexivity, preliminary results were discussed at a workshop held after data collection and preliminary analysis was completed.

Following completion of the interviews and focus groups, audio recordings were transcribed by the research assistants and field notes incorporated into the transcript. Transcripts were coded and analysed using the software Atlas.ti (Atlas.ti Scientific Software Development, Berlin, Germany). ${ }^{50}$ In keeping with a framework approach often used for qualitative, multidisciplinary health research, ${ }^{51-53}$ deductive themes were determined a priori based on our conceptual framework of overarching questions. Additional inductive themes were also identified on review of the transcripts. Deductive codes provided a useful way of comparing themes and concepts within and across countries. Text was coded and reviewed for patterns of consistency, variation, relationships between themes and exemplary cases or quotations. ${ }^{545}$

\section{Patient involvement}

Patients were not involved in the design of this study. Results were disseminated to $\mathrm{MOH}$ and WHO representatives from Liberia, and a presentation and report detailing results were made available to these representatives to aid further dissemination to other stakeholders.

\section{RESULTS}

\section{MNCH coverage indicators}

Indicator coverage data from 2000 were not available for 6 of the 13 core indicators (figure 2). Liberia has improved coverage of nine of these indicators during the study period. Highest current indicator coverage is seen for pregnant women receiving antenatal care (ANC) (96\%), vitamin A supplementation (88\%), pregnant women receiving at least four ANC visits (78\%) and improved water sources (75\%; figure 2). Coverage was below $50 \%$ for improved sanitation $(17 \%)$, postnatal visits within 2 days for deliveries $(35 \%)$, use of insecticide-treated bednets $(38 \%)$ and diarrhoea treatment (46\%; figure 2).

\section{National prioritisation of MNCH}

Both national documents and key informants at nearly all levels highlighted the strong commitment the Liberian government made to rebuild the healthcare system soon after the civil war ended. Key informants and national documents also described how MNCH was prioritised, not just within the $\mathrm{MOH}$, but also by top leadership throughout all sectors of the government. As an example of Liberia's high level commitment to MNCH, key informants described how maternal and neonatal deaths were reported directly to Liberia's president. Routine audits of maternal and neonatal deaths were undertaken by county health boards to identify problems with care and improve accountability and oversight. Community women rarely specifically commented on the government's prioritisation of MNCH, but some did express appreciation for the government's role in rebuilding services after the conflict. This prioritisation of MNCH by multiple levels in the government is illustrated in the quotations below:

I mean it has been a painfully slow process ... to get government to that level of commitment but a lot of progress, a lot of gain has been made and I can tell you for instance now the President of Liberia is the president of the commission for women health in Africa and that's under the WHO-AFRO, I can tell you that the government ... had made maternal and newborn health one of the conditions that will undergo surveillance, meaning that ... maternal and newborn death should be reported. (49years old, male donor partner)

... I think all the things we do medication and everything government has been involved [in] ... if you have anybody dying from giving birth they have this audit in this particular team that reports directly to the President of Liberia, so they are even involved in it ... (35years old, female from CBO partner)

[NGOs and the government] are giving us knowledge [on] how to take care of ourselves and what to do when you are pregnant, where to go and where not to go and what for you to eat ... things have improved, because we having NGOs, we having government, we having UN, many people coming in they helping us too. So things have improved bit by bit. (39years old, rural woman with four children)

Although child health has been recognised as an important priority by both the Liberian government and donor partners, national health documents and key informant interviews all indicated consistent concern that Liberia's high dependence on donor aid is unsustainable. Many key informants felt that the Liberian government's relationship with donors had evolved such that donors no longer drove the agenda, but rather accepted guidance from the government on priority areas and needs that the donors could assist with. However, there were also some who felt that donors continued to have too much involvement because of the high levels of funding they provided. Due to strong donor funding and some government funding, most $\mathrm{MNCH}$ services were free during much of the study period, which key informants and community women felt contributed to increased access and utilisation. However, key informants and national documents indicated that the government of Liberia needs to institutionalise services currently provided by external partners and take more financial responsibility for the health sector. The government was praised by a few participants for taking on a greater share of responsibilities, such as vaccine procurement, but many acknowledged that the 
government needed to sustain their involvement and investment to ensure gains were sustainable.

... we are donor dependent; the sources of funding either from the donor or the GOL [Government of Liberia] but what comes into the ministry for maternal and child health issue is very small but the input that partners are making if you count it, it's very huge. So we think that for sustainability the government needs to play more roles because if these partners leave, the gains that we are making, to sustain it might be difficult... (46years old, female MOH official)

\section{Development and implementation of integrated packages of} services

Key informants indicated that the MOH did a good job of implementing extensive reforms of the health system soon after the civil war, and continuous attempts to evaluate and update policies and strategies to make gradual improvements. An often-cited example by key informants of this process was the implementation of integrated packages of services, detailed in the quotations below:

... I think there is an enabling environment from the government through the Ministry of Health that is in place through the development of the ten years plan and the expanded program which is the EPHS [Expanded Package of Health Services], which addresses child health and maternal health, so first there is a will on the part of the government to address child health and maternal health ... (49years old, female donor partner)

... the Ministry of Health, from the beginning a postwar country had a policy first that was guiding the process; the BPHS [Basic Packages of Health Services].... So it had bases on how people should implement the policy and also as time went by, maternal services improved over time based on evaluation from the Ministry of Health and Social Welfare through their annual accreditation looking at service delivery. (35 years old, male donor partner)

Liberia's National Health Policy and $\operatorname{Plan}^{56}$ first focused on establishing the Basic Package of Health Services (BPHS). National documents and key informants attributed rapid scale-up of MNCH interventions immediately following the civil war to the effective framework set forth by the BPHS. According to national documents, the BPHS also aimed to improve distribution and supervision of healthcare providers through the establishment of a salary scale, standardised job descriptions and supervision tools for all cadres. Although the BPHS is credited with restoring $\mathrm{MNCH}$ service delivery across Liberia, several key informants stated that the BPHS did not adequately integrate services across different sectors of $\mathrm{MNCH}$, which they felt hindered delivery of maternal health and family planning, nutrition and prevention of mother-to-child transmission of HIV (PMTCT). Additionally, components of the BPHS intended to improve human resources for health were not fully implemented or did not appear to have the intended impact, as many key informants and community women cited a lack of qualified and quality providers.

Recognising the shortcomings of the BPHS, the National Health and Social Welfare Policy and Plan ${ }^{57}$ was developed and established the Essential Package of Health Services (EPHS) which aimed to scale-up interventions (especially MNCH interventions), reduce inequities, improve collaboration across different sectors and improve quality at secondary and tertiary healthcare centres. The EPHS also sought to increase the number of skilled workers available for labour and delivery to ensure that emergency obstetric and neonatal care is available at all facilities. Key informants were quite positive about the EPHS, feeling that it had improved collaboration between sectors and had improved quality of care in some areas. Some key informants also felt that the clearer language in the policy documents enabled the government to better establish expectations and hold partners accountable when implementation goals were not met.

... from the BPHS to EPHS, it was EPHS they were able to strengthen that MCH part to include in addition to nutrition, adolescence, reproductive health care and all of that sexual health but in the past, those were very weak and gray areas; as long as the policy did not address them, they became difficult for anyone to hold a partner accountable for any implementation. Uh, now, the ministry has included that and there are more services. (47years old, male CBO partner)

However, some key informants felt that the EPHS had not been completely implemented at all levels, particularly the primary care level, due to lack of resources, both human and financial. The incomplete implementation limits not only delivery of $\mathrm{MNCH}$ interventions but also the collaboration and coordination the EPHS was intended to promote. In addition, both key informants and some community women described continued shortages of healthcare providers, especially those trained in delivery-related interventions, certified midwives and paediatric specialists outside the capital of Monrovia. As illustrated below, community women and key informants noted that limited availability of $\mathrm{MNCH}$ providers and poor attitudes of providers remained a barrier to using and accessing care.

... When I gave birth, the girl that attended to me because she left, her shift was over ... that night I could die because I started bleeding right after giving birth. But because my friend was a nurse she went there and attended to me that night. Those that were on shift that night ... never had time for me because nothing was there for me to tip in, so they just acted careless on [with] me. (38years old, urban woman with four children)

Clinics are ... not running 24/7 services, we have heard these challenges from them, people go 
overnight with complaints and the health care provider says I am not paid for overnight services so you have to wait until tomorrow; so lack of motivation at the service provider end is also impeding the process. (37 years old, male CBO partner)

Although key informants were concerned about incomplete implementation of the EPHS, they attributed improvements in malaria, PMTCT services, nutrition and reproductive health to the enhanced integration between sectors that the EPHS provided, as illustrated below. Community women did not specifically describe implementation of the EPHS or differentiate between levels of the healthcare system, but did discuss the quality of care they received. Specifically, women felt very positive about the care received during pregnancy and delivery, as well as educational and preventive services.

... I think it has changed ... in the past we had the BPHS that provided minimum service at the health facility where when the pregnant woman comes, they only check them and when they have malaria, they treat them and they go home. But this time around, the BPHS has been modified to EPHS and where, we look at a full package, the standards have improved, the services have improved and they receive a whole package and deliver it to the mother ... [including] PMTCT services, immunization, nutrition, and other laboratory findings so as to reduce the number of visits, she has to do at the health facility. (33years old, male MOH official)

... the nurses and the doctors especially at the hospital here, whenever they carry pregnant woman there, they always cater to the person and talk [to] the person in a polite manner, try to help the person ... They always treat us free and at time [delivery] they give baby's clothes free of charge. (43year old, rural woman with six children)

... when you give birth and the baby is growing up, you don't have to wait for the child to fall sick before you carry the child to hospital. You can take the child to hospital so the child will get drugs [anti-malaria prophylaxis] ... (35 years old, urban woman with four children)

\section{Community outreach and service delivery}

Liberia's use of community outreach and service delivery was a third overarching factor identified as facilitating achievement of MDG 4. The national Community Health Services Policy first issued in 2008 and revised in $2011^{58}$ outlined a standard set of outreach, health promotion and referral services. This policy also specified the roles and responsibilities of community-based staff including general community health volunteers (GCHVs) and trained traditional midwives (TTMs). It further outlined how they should be distributed geographically, supervised, evaluated and that TTMs are to be compensated with monthly salaries while GCHVs work as volunteers but receive an incentive package. Both key informants and community women were positive about their efforts at the community level, recognising how these cadres enhance referrals from the community to healthcare facilities and follow-up with mothers and children in the community after they return home. GCHVs and TTMs were also highly valued by community women for their assistance with the outreach campaigns-'Reach Every District' (RED) and 'Reach Every Pregnancy' (REP)—to improve immunisation coverage and maternal health, respectively. Both key informants and community women further described that GCHVs and TTMs had likely increased coverage of antenatal and postnatal care by connecting women with the healthcare system earlier in pregnancy and increased immunisation coverage through mobile vaccination sites, and improved community-based education and communication.

... the vaccine team most of the time come around to give our children vaccine and deworm them with the medicine. At time we can see some people with the megaphone educating ... pregnant women on how to take care of your children and even how to take care of your community. As for the health campaign we can see them and we can benefit from them. (38 years old, urban woman with three children)

Number one thing that is trying to work well is the TTMs and GCHVs, they are trying their best with the referrals. They get any patient in the community, they bring them here ... we have family planning, we have EPI under MCH, we have PMTCT, ANC, labor and delivery, post-partum care provided .... The only problem we have with our GCHVs is that they are saying they are not been compensated so we don't expect them to work full time. (43years old, female healthcare worker)

While attributing success at the community level to the efforts of GCHVs and TTMs, study participants also felt these staff needed better compensation beyond what is currently provided to enable them to work more often. The insufficient number of GCHVs and TTMs was also cited as a challenge affecting availability of health services. Key informants and national documents noted that due to limited human and financial resources, local health clinics were not always staffed and community-based interventions such as the RED and REP campaigns had not been implemented or adequately supported in all areas.

... I remember some time ago they were trying to integrate the ... reach every pregnant women; reach every district ... but for the reach every pregnant woman actually it is not working $100 \%$. If I will have to grade it may be it is working around $40 \%$ to $45 \%$ because of may be some supplies that supposed to be given or put into place it is not into place... (34years old, female CBO partner) 


\section{DISCUSSION}

This case study identifies three components that have likely contributed to Liberia's rapid post-conflict decline in under-five mortality and attainment of MDG 4. First, the Liberian government made re-establishment and funding of MNCH a top priority as it rebuilt its health system after the civil war. Second, the development and implementation of integrated packages of services, first the BPHS followed by the EPHS, enabled Liberia to restore basic MNCH services and scale-up interventions at all levels of the healthcare system. The development and implementation of the BPHS and EPHS also demonstrated Liberia's ability to evaluate and rework policies and strategies. The EPHS fostered further integration and collaboration across multiple sectors, which allowed for the expansion of PMTCT, nutrition and other MNCH services. The EPHS also sought to improve the availability of trained health workers and fully functional health units, although challenges persisted despite these efforts. Third, provision of services at the community level, such as outreach campaigns and use of GHCVs and TTMs to deliver basic $\mathrm{MNCH}$ interventions, contributed to improved coverage of ANC, postnatal care and immunisations and also improved access and continuity of care in post-conflict Liberia by strengthening referrals between the community and healthcare facilities.

Liberia used a healthcare system recovery approach that has shown promise in other post-conflict or conflict-affected settings. Specifically, Kruk et al ${ }^{12}$ emphasise the need for strong national leadership and governance that makes restoration of basic health services a top national priority. They also documented that, when a national government makes a strong commitment to providing healthcare to the most vulnerable populations (such as women and children), this commitment can contribute to the country's long-term stability and recovery efforts. A BPHS enabling rapid roll-out and scale-up of MNCH and other primary health services has also been deployed with some success in Afghanistan, South Sudan, Rwanda, and Bosnia and Herzegovina ${ }^{59-63}$ and is specifically recommended for conflict-affected settings. ${ }^{412}$ These packages of services typically include key MNCH interventions, nutrition and treatment for communicable diseases (such as tuberculosis and HIV). ${ }^{59-65}$ Afghanistan, like Liberia, revised their basic package to also include additional services (for disability and mental health), recognising the specific needs of their population and the gaps in their original package. Researchers have suggested that integrated packages of services may help in initial scale-up and improvements, but require additional inputs and adjustments to sustain these improvements..$^{5066266}$

Community-level education, empowerment and outreach are also recommended to improve utilisation and access to basic interventions and improve referrals from the community to the facility levels. ${ }^{467-70}$ Expanding cadres of traditional birth attendants and community health workers has been found to be particularly key in restoring maternal and neonatal services in conflict-affected settings. ${ }^{59}{ }^{71-75}$ Community health workers and community-level outreach and service delivery has also been a key factor in the successes of other countries successfully reducing child mortality. ${ }^{30-34} 3876$ Although many conflict-affected settings have difficulties with referrals, ${ }^{67778}$ this is one area where Liberia appears to have made great progress through their use of GCHVs and TTMs, as described by key informants and community women.

Although Liberia has made significant progress in MNCH, national documents and study participants noted a number of challenges that persist and need to be addressed as Liberia moves forward to achieve their post-2015 goals. ${ }^{27}$ This includes their severe shortage of healthcare providers, particularly community-based midwives and child health providers in rural areas. The lack of healthcare providers and challenges associated with training and retaining general and $\mathrm{MNCH}$ providers is well-documented in the literature from other conflict-affected countries where brain-drain is common during and after conflict. ${ }^{4} 12596769$ 79-82 Another weakness described in the study is Liberia's high dependence on donor aid to provide many of the MNCH services. Although heavy reliance on donor aid is consistent with other conflict-affected countries, there is little consensus on how donors can best support post-conflict countries and few recommendations as to how and when post-conflict settings should make the transition from donor-provided services to government-provided services. ${ }^{83-85}$ An emphasis on increased government stewardship of the healthcare system, particularly with respect to the government taking a key role in determining partner expectations and roles and contracting directly with partners comprises one set of recommendations. ${ }^{86-88}$ Liberia's relationships with donors appears to have evolved in line with this recommendation; however, additional progress is still needed. The literature also cautions that the time horizon for moving away from donor dependence in conflict-affected states may be lengthy and is not necessarily linear as a state's stability may not always follow a linear trajectory. ${ }^{84} 86$

This study provides one of the few country-case studies to assess progress towards achieving MDG 4. Perhaps more importantly, it provides much needed insight into MNCH infrastructure and experiences from an understudied, post-conflict, yet highly successful African country. This case study used a number of data sources, including national indicator data, country-authored health policies and strategies, and qualitative data from key informants with different roles in $\mathrm{MNCH}$ and four focus group discussions with women from urban and rural areas. By bringing together diverse sources of data, this study was able to assess the national-level measures used to enhance child survival and the facilitators and challenges that affected full implementation and impact.

There are limitations in our study. For the review of national $\mathrm{MNCH}$ policies and strategies, new policies and strategies were not issued until after 2007 due to 
the civil war. While these documents contained a retrospective assessment of the preceding period, assessments of the impact of more recent policies or strategies were not yet available. Moreover, country policies and strategies covered different and sometimes overlapping time periods, making it difficult to distinguish current from outdated information, and whether a stated plan had been implemented unless stated. Input from coauthors affiliated with the $\mathrm{WHO}$ and the $\mathrm{MOH}$ helped to clarify uncertainty.

With regards to the interviews and focus groups, this study was limited to a non-random sample of participants and conducted in two counties (one urban, one rural). Changes in under-five mortality in these areas may not reflect changes at the national level and local views and experiences may not reflect those from other areas. However, participants were selected to represent five different cadres of individuals who could share a diversity of MNCH experiences, including some key informants with national-level responsibilities and 37 women from the community. Most of the participants recalled their current experiences and opinions on $\mathrm{MNCH}$, and we gained less insight as to long-term changes.

Our study contributes to the growing literature on effective approaches to scaling up availability and use of $\mathrm{MNCH}$ services in conflict-affected settings. The factors identified as contributing to Liberia's success in reducing under-five mortality can be applied in the many other countries recovering from conflict and is relevant to Liberia's recovery from the 2014-2015 Ebola epidemic. To further improve the delivery of essential health services and reduce under-five mortality in the post-2015 era, Liberia must maintain the health and welfare of pregnant women and children as a top priority, conduct comprehensive evaluation and enhancement of programmes and interventions, increase government responsibility for service delivery to reduce donor dependence and ensure that sufficient human and financial resources enable $\mathrm{MNCH}$ service delivery close to the population.

\section{Author affiliations}

${ }^{1}$ Department of Anthropology, University of Connecticut, Storrs, Connecticut, USA ${ }^{2}$ University of Liberia-Pacific Institute for Research and Evaluation (UL-PIRE) Africa Center, University of Liberia, Monrovia, Liberia

${ }^{3}$ Vanderbilt Institute for Global Health, Vanderbilt University, Nashville, Tennessee, USA

${ }^{4}$ Department of Medicine, Vanderbilt University Medical Center, Nashville, Tennessee, USA

${ }^{5}$ Liberia Ministry of Health and Social Welfare, Monrovia, Liberia

${ }^{6}$ Liberia Country office, World Health Organization, Monrovia, Liberia

${ }^{7}$ Regional Office for Africa, World Health Organization, Brazzaville, Congo

${ }^{8}$ Department of Pediatrics, Vanderbilt University Medical Center, Nashville,

Tennessee, USA

Acknowledgements We thank the African Region of the WHO for their support for this research and the research participants for sharing their time, experiences and opinions. We also acknowledge research assistants Wede $\mathrm{M}$ Nagbe and Curtis $\mathrm{H}$ Taylor for the qualitative portion of the study and also who conducted and transcribed the interviews and focus group discussions.

Contributors MAB: Involved in conceptualisation of research, development of methodology, data collection, data analysis, data management and manuscript development. SBK: Involved in the development of methodology, data collection, data management and manuscript development. CAH: Involved in conceptualisation of research, development of methodology, data collection, data analysis, data management and manuscript development. ATC: Involved in development of methodology, provision of study resources and manuscript development. MCD: Involved in development of methodology, provision of study resources and manuscript development. PH: Involved in conceptualisation of research, development of methodology, funding acquisition and manuscript development. SHV: Involved in conceptualisation of research, development of methodology, funding acquisition and manuscript development. AMK: Involved in conceptualisation of research, project administration, development of methodology, funding acquisition, data collection, data analysis, data management and manuscript development. KM: Involved in conceptualisation of research, project administration, development of methodology, funding acquisition, provision of study resources and manuscript development.

Funding Funding for this project was provided by the WHO Regional Office for Africa. Support for data management came from the Vanderbilt Institute for Clinical and Translational Research (grant UL1 TR000445 from the National Center for Advancing Translational Sciences at the National Institutes of Health). AMK was supported through an award from the National Institute on Drug Abuse at the National Institutes of Health (R25 DA035692).

Competing interests ATC is an employee of Liberia's Ministry of Health. PH and $\mathrm{KM}$ are employees of the WHO. At the time of the study, AMK was a scholar with the HIV/AIDS, Substance Abuse and Trauma Training Programme (HA-STTP) at the University of California, Los Angeles, California.

Patient consent Not required.

Ethics approval Vanderbilt University Medical Center and the University of LiberiaPacific Institute for Research and Evaluation.

Provenance and peer review Not commissioned; externally peer reviewed.

Data sharing statement Annual mortality estimates used in Figure 1 are publicly available, without restriction, from http://www.childmortality.org/index.php?r= site/graph\#ID=LBR_Liberia. Indicator data used for Figure 2 are publicly available, without restriction, from the World Development Index, Africa Development Index and Health Nutrition \& Population Statistics databases of the World Bank Data Catalog (http://data.worldbank.org/data-catalog/) or Liberia Demographic and Health Survey reports available at http://dhsprogram.com/Where-We-Work/ Country-Main.cfm?ctry_id=22\&c=Liberia\&r=1. A detailed description of each indicator's source can be found in the supplemental material from a previously published study (Kipp et al, BMJ Open, 2016, http://dx.doi.org/10.1136/bmjopen2015-007675). Online supplemental table S1 lists the national documents reviewed for the study. These were obtained with the permission and assistance of the Liberian co-authors and do not belong to any of the individual study authors. As such, they cannot be made available as they belong to the Ministry of Health or other agencies and some are still in draft form. Links to publicly available documents are provided in online supplemental table S1. For investigators wishing to obtain other policy documents used in this study, please contact Mr Luke Bawo, Coordinator for Research and Health Management Information System, Ministry of Health, email: lukebawo@gmail.com; or Hon. C Sanford Wesseh, Assistant Minister for Vital Statistics, Ministry of Health, email: cswesseh@yahoo.com. Under the Agreement for Performance of Work with the WHO (sponsor) that was used for this study, all rights to the data collected from key informants and community women belong to the WHO. The WHO will entertain any reasonable proposal for use of the data. Researchers who are qualified to manage and analyse qualitative data may request these data from the author PH, Team Leader, Child and Adolescent Health and Nutrition, WHO Regional Office for Africa, Brazzaville, Congo; email: habimanap@who.int. Interview, focus group discussion and national document abstraction guides are available on request from the corresponding author; email: aaron.kipp@vanderbilt.edu. These data are not considered part of the underlying data necessary to replicate the study.

Author note These researchers have changed affiliation since this research was conducted. Their current affiliations are as follows: *Marie Brault is now at the Social and Behavioral Sciences Department, Yale School of Public Health, New Haven, CT, USA; *Connie Haley is now at the Division of Infectious Diseases and Global Medicine, University of Florida, Gainesville, FL, USA; *Sten Vermund is now at the Epidemiology of Microbial Diseases Department, Yale School of Public Health, and Department of Pediatrics, Yale School of Medicine, New Haven, CT, USA; *Kasonde Mwinga is now at the World Health Organization, India Country Office, New Delhi, India. 
Open access This is an open access article distributed in accordance with the Creative Commons Attribution Non Commercial (CC BY-NC 4.0) license, which permits others to distribute, remix, adapt, build upon this work non-commercially, and license their derivative works on different terms, provided the original work is properly cited, appropriate credit is given, any changes made indicated, and the use is non-commercial. See: http://creativecommons.org/licenses/by-nc/4.0/.

\section{REFERENCES}

1. UNICEF, WHO, World Bank. Levels and trends in child mortality: report 2015 - estimates developed by the United Nations interagency group for child mortality estimation. New York: UNICEF, 2015. (accessed Jul 2015)

2. United Nations. United Nations millenium declaration: United Nations. 2000. http://www.un.org/millennium/declaration/ares552e. htm (accessed Feb 2013).

3. Liberia Ministry of Health and Social Welfare (MoHSW). Country situational analysis report. Monrovia, Liberia: Ministry of Health and Social Welfare, 2011

4. Bornemisza O, Ranson MK, Poletti TM, et al. Promoting health equity in conflict-affected fragile states. Soc Sci Med 2010;70:80-8.

5. Tubman VN, Marshall R, Jallah W, et al. Newborn screening for sickle cell disease in Liberia: a pilot study: newborn screening for sickle cell in Liberia. Pediatric Blood \& Cancer 2016;63:671-6.

6. Tsai C, Walters C, Sampson J, et al. Pediatric mortality in a rural tertiary care center in Liberia. Children 2017;4:8.

7. Sipsma H, Callands TA, Bradley E, et al. Healthcare utilisation and empowerment among women in Liberia. J Epidemiol Community Health 2013:67:953-9.

8. Luginaah IN, Kangmennaang J, Fallah M, et al. Timing and utilization of antenatal care services in Liberia: Understanding the pre-Ebola epidemic context. Soc Sci Med 2016;160:75-86.

9. Kenny A, Basu G, Ballard M, et al. Remoteness and maternal and child health service utilization in rural Liberia: a population-based survey. J Glob Health 2015;5:48-59.

10. Gartland MG, Taryor VD, Norman AM, et al. Access to facility delivery and caesarean section in north-central Liberia: a cross-sectional community-based study. BMJ Open 2012;2:e001602.

11. Kentoffio K, Kraemer JD, Griffiths T, et al. Charting health system reconstruction in post-war Liberia: a comparison of rural vs. remote healthcare utilization. BMC Health Serv Res 2016;16:478.

12. Kruk ME, Rockers PC, Williams EH, et al. Availability of essential health services in post-conflict Liberia. Bull World Health Organ 2010;88:527-34.

13. Lori JR, Rominski S, Osher BF, et al. A case series study of perinatal deaths at one referral center in rural post-conflict Liberia. Matern Child Health J 2014;18:45-51.

14. Smith JM, Baawo SD, Subah M, et al. Advance distribution of misoprostol for prevention of postpartum hemorrhage (PPH) at home births in two districts of Liberia. BMC Pregnancy Childbirth 2014;14:189.

15. Solanke BL, Amoo EO, Idowu AE. Improving postnatal checkups for mothers in West Africa: a multilevel analysis. Women \& Health 2017:1-25.

16. Lori JR, Munro ML, Moore JE, et al. Lessons learned in Liberia: preliminary examination of the psychometric properties of trust and teamwork among maternal healthcare workers. BMC Health Serv Res 2013;13:134.

17. Lori JR, Munro-Kramer ML, Shifman J, et al. Patient satisfaction with maternity waiting homes in liberia: a case study during the ebola outbreak. J Midwifery Womens Health 2017;62:163-71.

18. Lori JR, Starke AE. A critical analysis of maternal morbidity and mortality in Liberia, West Africa. Midwifery 2012;28:67-72.

19. Lori JR, Wadsworth AC, Munro ML, et al. Promoting access: the use of maternity waiting homes to achieve safe motherhood. Midwifery 2013;29:1095-102.

20. Cooper CM, Fields R, Mazzeo Cl, et al. Successful proof of concept of family planning and immunization integration in Liberia. Global Health: Science and Practice 2015;3:71-84.

21. Guyon A, Bock A, Buback L, et al. Mobile-Based nutrition and child health monitoring to inform program development: an experience from Liberia. Global Health: Science and Practice 2016;4:661-70.

22. Munro ML, Lori JR, Boyd CJ, et al. Knowledge and skill retention of a mobile phone data collection protocol in Rural Liberia. J Midwifery Womens Health 2014;59:176-83.

23. Luckow PW, Kenny A, White E, et al. Implementation research on community health workers' provision of maternal and child health services in rural Liberia. Bull World Health Organ 2017;95:113-20.
24. Lori JR, Majszak CM, Martyn KK. Home-Based life-saving skills in Liberia: acquisition and retention of skills and knowledge. J Midwifery Womens Health 2010;55:370-7.

25. Lori JR, Munro ML, Rominski S, et al. Maternity waiting homes and traditional midwives in rural Liberia. J Gynaecol Obstet 2013;123:114-8.

26. Shoman H, Karafillakis E, Rawaf S. The link between the West African Ebola outbreak and health systems in Guinea, Liberia and Sierra Leone: a systematic review. Global Health 2017;13.

27. lyengar P, Kerber K, Howe CJ, et al. Services for mothers and newborns during the ebola outbreak in liberia: the need for improvement in emergencies. PLoS Curr 2015;7.

28. Ly J, Sathananthan V, Griffiths T, et al. Facility-Based delivery during the ebola virus disease epidemic in rural Liberia: analysis from a cross-sectional, population-based household survey. PLoS Med 2016;13:e1002096.

29. Fallah MP, Skrip LA, Dahn BT, et al. Pregnancy outcomes in Liberian women who conceived after recovery from Ebola virus disease. Lancet Glob Health 2016;4:e678-9.

30. Mbonye AK, Sentongo M, Mukasa GK, et al. Newborn survival in Uganda: a decade of change and future implications. Health Policy Plan 2012;27:iii104-17.

31. Kuruvilla S, Schweitzer J, Bishai D, et al. Success factors for reducing maternal and child mortality. Bull World Health Organ 2014;92:533-44.

32. Afnan-Holmes H, Magoma M, John T, et al. Tanzania's Countdown to 2015: an analysis of two decades of progress and gaps for reproductive, maternal, newborn, and child health, to inform priorities for post-2015. Lancet Glob Health 2015;3:e396-409.

33. Amouzou A, Habi O, Bensaïd K, et al. Reduction in child mortality in Niger: a countdown to 2015 country case study. The Lancet 2012;380:1169-78.

34. Zimba E, Kinney MV, Kachale F, et al. Newborn survival in Malawi: a decade of change and future implications. Health Policy Plan 2012;27:iii88-103.

35. Brault MA, Ngure K, Haley CA, et al. The introduction of new policies and strategies to reduce inequities and improve child health in Kenya: A country case study on progress in child survival, 20002013. PLoS One 2017;12:e0181777.

36. Haley CA, Vermund SH, Moyo P, et al. Impact of a critical health workforce shortage on child health in Zimbabwe: a country case study on progress in child survival, 2000-2013. Health Policy Plan 2017;4:Czw162.

37. Kipp AM, Blevins M, Haley CA, et al. Factors associated with declining under-five mortality rates from 2000 to 2013: an ecological analysis of 46 African countries. BMJ Open 2016;6:e007675.

38. Kipp AM, Maimbolwa M, Brault MA, et al. Improving access to child health services at the community level in Zambia: a country case study on progress in child survival, 2000-2013. Health Policy Plan 2016;2:czw141.

39. World Bank. The World Bank Data catalog. http://datacatalog. worldbank.org/ (accessed Aug 2015).

40. Liberia Institute of Statistics and Geo-Information Services (LISGIS), Ministry of Health and Social Welfare [Liberia], National AIDS Control Program [Liberia]. Liberia Demographic and Health Survey 2013. Monrovia, Liberia: LISGIS and ICF International, 2014.

41. Liberia Institute of Statistics and Geo-Information Services (LISGIS) [Liberia], Ministry of Health and Social Welfare [Liberia], National AIDS Control Program [Liberia]. Liberia Demographic and Health Survey 2007. Monrovia, Liberia: Liberia Institute of Statistics and Geo-Information Services (LISGIS) and Macro International Inc, 2008.

42. WHO. Child survival: a strategy for the African region. Brazzaville: World Health Organization, Regional Office for Africa, 2006.

43. Organization WH. Everybody's business-strengthening health systems to improve health outcomes: WHO's framework for action. 2007.

44. Ban K. Global Strategy for Women's and Children's Health. New York: United Nations, 2010.

45. WHO and UNICEF. Countdown to 2015 Decade Report (2000-2010): taking stock of maternal, newborn, and child survival. 2010.

46. WHO, PMNCH. A global review of the key interventions related to reproductive, maternal, newborn and child health (RMNCH). Geneva, Switzerland: WHO and The Partnership for Maternal Newborn \& Child Health (PMNCH), 2011.

47. Organization WH. Keeping promises, measuring results: commission on information and accountability for women's and children's health: World Health Organization, 2012.

48. Chieh-Johnson D, Cross A, Way A, et al. Liberia Demographic and Health Survey 1986. Columbia, Maryland, USA: Monrovia, Liberia and Columbia, Maryland: Bureau of Statistics [Liberia], Ministry 
of Planning and Economic Affairs, and Institute for Resource Development/Westinghouse, 1988.

49. Collins D. Pretesting Survey Instruments: An Overview of Cognitive Methods. Quality of Life Research 2003:12:229-38.

50. Murh T. User's Manual for Atlas. ti 6.0. Berlin: Atlas ti, 2004.

51. Bradley EH, Curry LA, Devers KJ. Qualitative Data Analysis for Health Services Research: Developing Taxonomy, Themes, and Theory. Health Serv Res 2007;42:1758-72.

52. Gale NK, Heath G, Cameron E, et al. Using the framework method for the analysis of qualitative data in multi-disciplinary health research. BMC Med Res Methodol 2013;13:117.

53. LeCompte MD, Schensul JJ. Analysis and interpretation of ethnographic data: A mixed methods approach: Rowman Altamira. 2012.

54. Nastasi BK, Schensul SL. Contributions of qualitative research to the validity of intervention research. J Sch Psychol 2005;43:177-95.

55. Schensul SL. Using Ethnograph to build a survey instrument. CAM 1993;5:9.

56. Liberia Ministry of Health and Social Welfare (MoHSW). The National Health Policy and Plan, 2007-2011. Monrovia, Liberia: Ministry of Health and Social Welfare, 2007.

57. Liberia Ministry of Health and Social Welfare (MoHSW). National Health and Social Welfare Policy and Plan 2011-2021. Monrovia, Liberia: Ministry of Health and Social Welfare, 2011.

58. Liberia Ministry of Health and Social Welfare (MoHSW). Revised National Community Health Services Policy. Monrovia, Liberia: Ministry of Health and Social Welfare, 2011.

59. Howard N, Woodward A, Patel D, et al. Perspectives on reproductive healthcare delivered through a basic package of health services in Afghanistan: a qualitative study. BMC Health Serv Res 2014;14:359.

60. Roberts B, Guy S, Sondorp E, et al. A basic package of health services for post-conflict countries: implications for sexual and reproductive health services. Reprod Health Matters 2008;16:57-64.

61. Hrabac B, Ljubic B, Bagaric I. Basic package of health entitlements and solidarity in the Federation of Bosnia and Herzegovina. Croatian medical journal 2000;41:287-93.

62. Newbrander W, Ickx P, Feroz F, et al. Afghanistan's basic package of health services: its development and effects on rebuilding the health system. Global public health 2014;9:S6-S28.

63. Newbrander W, Waldman R, Shepherd-Banigan M. Rebuilding and strengthening health systems and providing basic health services in fragile states. Disasters 2011;35:639-60.

64. Liberia Ministry of Health and Social Welfare (MoHSW). Essential package of health services for primary care: the community health system. Monrovia, Liberia: Ministry of Health and Social Welfare, 2011.

65. Liberia Ministry of Health and Social Welfare (MoHSW). Essential package of health services for secondary \& tertiary care: the district, county \& national health systems. Monrovia, Liberia: Ministry of Health and Social Welfare, 2011.

66. Petit D, Sondorp E, Mayhew S, et al. Implementing a basic package of health services in post-conflict Liberia: perceptions of key stakeholders. Soc Sci Med 2013;78:42-9.

67. Leather A, Ismail EA, Ali R, et al. Working together to rebuild health care in post-conflict Somaliland. The Lancet 2006;368:1119-25.

68. Morikawa MJ, Schneider S, Becker S, et al. Primary care in postconflict rural northern Afghanistan. Public Health 2011;125:55-9.

69. Nagai M, Abraham S, Okamoto M, et al. Reconstruction of health service systems in the post-conflict Northern Province in Sri Lanka. Health Policy 2007;83:84-93.

70. Ls H, Labrecque G, Batonon I, et al. Effects of a community scorecard on improving the local health system in Eastern
Democratic Republic of Congo: qualitative evidence using the most significant change technique. Conflict and Health 2015;9:27.

71. Gopalan SS, Das A, Howard N. Maternal and neonatal service usage and determinants in fragile and conflict-affected situations: a systematic review of Asia and the Middle-East. BMC Womens Health 2017;17.

72. Krause SK, Meyers JL, Friedlander E. Improving the availability of emergency obstetric care in conflict-affected settings. Glob Public Health 2006;1:205-28.

73. Miyake S, Speakman EM, Currie S, et al. Community midwifery initiatives in fragile and conflict-affected countries: a scoping review of approaches from recruitment to retention. Health Policy Plan 2017;32:21-33.

74. Mullany LC, Lee TJ, Yone L, et al. Impact of community-based maternal health workers on coverage of essential maternal health interventions among internally displaced communities in Eastern Burma: the MOM project. PLoS Med 2010;7:e1000317.

75. Teela KC, Mullany LC, Lee $\mathrm{Cl}$, et al. Community-based delivery of maternal care in conflict-affected areas of eastern Burma: Perspectives from lay maternal health workers. Soc Sci Med 2009:68:1332-40.

76. Moucheraud C, Owen H, Singh NS, et al. Countdown to 2015 country case studies: what have we learned about processes and progress towards MDGs 4 and 5 ? BMC Public Health 2016;16(S2):794.

77. Fernando D, de Silva NL, Ackers I, et al. Patient satisfaction and uptake of private-sector run malaria diagnosis clinics in a postconflict district in Sri Lanka. BMC Public Health 2014;14:641.

78. Chi PC, Bulage P, Urdal H, et al. Barriers in the delivery of emergency obstetric and neonatal care in post-conflict Africa: qualitative case studies of Burundi and Northern Uganda. PLoS One 2015;10:e0139120.

79. Balalian AA, Simonyan H, Hekimian $\mathrm{K}$, et al. Adapting continuing medical education for post-conflict areas: assessment in Nagorno Karabagh - a qualitative study. Hum Resour Health 2014;12:39.

80. Chandrasekhar S, Gebreselassie T, Jayaraman A. Maternal Health Care Seeking Behavior in a Post-Conflict HIPC: The Case of Rwanda. Popul Res Policy Rev 2011;30:25-41.

81. Mwaka AD, Wabinga HR, Mayanja-Kizza H. Mind the gaps: a qualitative study of perceptions of healthcare professionals on challenges and proposed remedies for cervical cancer helpseeking in post conflict northern Uganda. BMC Fam Pract 2013;14:193.

82. Roome E, Raven J, Martineau T. Human resource management in post-conflict health systems: review of research and knowledge gaps. Confl Health 2014;8:18.

83. Bank W. World Bank Group assistance to low-income fragile and conflict-affected states: an independent evaulation: The World Bank. 2015.

84. Addison T, McGillivray M. Aid to conflict-affected countries: lessons for donors. Conflict, Security \& Development 2004;4:347-67.

85. Hill PS, Pavignani E, Michael M, et al. The "empty void" is a crowded space: health service provision at the margins of fragile and conflict affected states. Confl Health 2014;8:20.

86. Witter S. Health financing in fragile and post-conflict states: What do we know and what are the gaps? Soc Sci Med 2012;75:2370-7.

87. Fujita N, Zwi AB, Nagai M, et al. A comprehensive framework for human resources for health system development in fragile and postconflict states. PLoS Med 2011;8:e1001146.

88. Alonso A, Brugha R. Rehabilitating the health system after conflict in East Timor: a shift from NGO to government leadership. Health Policy Plan 2006;21:206-16. 